\title{
Oral ketamine for the treatment of pain and treatment-resistant depression ${ }^{\dagger}$
}

Robert A. Schoevers, Tharcila V. Chaves, Sonya M. Balukova,

Marije aan het Rot and Rudie Kortekaas

\section{Background}

Recent studies with intravenous (i.v.) application of ketamine show remarkable but short-term success in patients with MDD. Studies in patients with chronic pain have used different ketamine applications for longer time periods. This experience may be relevant for psychiatric indications.
Aims
To review the literature about the dosing regimen, duration effects and side-effects of oral, intravenous, intranasal and subcutaneous routes of administration of ketamine for treatment-resistant depression and pain.

\section{Method}
Searches in PubMed with the terms 'oral ketamine', 'depression', 'chronic pain', 'neuropathic pain', 'intravenous ketamine', 'intranasal ketamine' and 'subcutaneous ketamine' yielded 88 articles. We reviewed all papers for information about dosing regimen, number of individuals who received ketamine, number of ketamine days per study, results and side-effects, as well as study quality.

\section{Results}

Overall, the methodological strength of studies investigating the antidepressant effects of ketamine was considered low, regardless of the route of administration. The doses for depression were in the lower range compared with studies that investigated analgesic use. Studies on pain suggested that oral ketamine may be acceptable for treatment-resistant depression in terms of tolerability and side-effects.

\section{Conclusions}

Oral ketamine, given for longer time periods in the described doses, appears to be well tolerated, but few studies have systematically examined the longer-term negative consequences. The short- and longer-term depression outcomes as well as side-effects need to be studied with rigorous randomised controlled trials.

\section{Declaration of interest}

None.

\section{Copyright and usage}

(C) The Royal College of Psychiatrists 2016.
The rapid antidepressant action of the glutamatergic $N$-methyl-Daspartate (NMDA) receptor antagonist ketamine has kindled great interest and optimism among researchers, clinicians and patients. ${ }^{1,2}$ Both open-label studies and small randomised controlled trials (RCTs) in treatment-resistant unipolar or bipolar depression have shown antidepressant effects occurring within hours of intravenous (i.v.) infusion with ketamine. This supports the idea that, besides the monoaminergic systems, the glutamatergic system may also be targeted for the treatment of major depressive disorder (MDD). ${ }^{3}$ In patients with mood disorders, glutamate levels in the serum and cerebrospinal fluid are altered. ${ }^{4}$ Ketamine increases the presynaptic release of glutamate, resulting in higher extracellular levels of glutamate by a combination of disinhibition of the neurotransmitter $\gamma$-aminobutyric acid (GABA) and blockage of the NMDA receptors at the phencyclidine binding site within the ion channel. ${ }^{5}$ This increase in extracellular glutamate release favours coexpressed $\alpha$-amino-3-hydroxy-5-methyl-4-isoxazolepropionic acid (AMPA), resulting in 'an increased glutamatergic throughput of AMPA relative to NMDA. ${ }^{5}$ The glutamatergic system is also fundamental for neuroplasticity, which is linked to mood disorders. ${ }^{6}$ NMDA receptor activation is part of the induction process for long-term potentiation, an important form of synaptic plasticity. Synapse-associated proteins and the number of dendritic spines then increase, for example, in the prefrontal cortex, ${ }^{7}$ thus reversing the structural and functional deficits resulting from long-term stress exposure. ${ }^{8}$

In treatment-resistant unipolar or bipolar depression studies, ketamine has mostly been administered intravenously. ${ }^{9}$ A rapid i.v. infusion of ketamine for treatment-resistant unipolar or bipolar depression, usually at a dose of $0.5 \mathrm{mg} / \mathrm{kg}$, leads to an

†See editorial, pp. 101-103, this issue. immediate bioavailability of $100 \%$. To date, six double-blind, crossover RCTs have been published that compared a single dose of i.v. ketamine with placebo. (Five of them used an inactive placebo - saline $e^{2,10-13}$ - and one used an active placebo midazolam. ${ }^{14}$ ) Overall, these studies showed rapid initial effects (40 min after infusion) that increase to 1 day post-infusion, but overall the difference between ketamine and placebo (inactive or active) was no longer statistically significant at 7 days postinfusion. A recent open-label study that compared ketamine with active placebo (midazolam) had a similar effect size of 0.81 at 1 day post-infusion, but again the effect did not last. ${ }^{15}$ The great challenge with ketamine as an antidepressant is to extend its duration of action.

To study the efficacy of repeated ketamine infusions, a nonblinded study provided six infusions over 2 weeks. After the last infusion, 8 of 9 patients $(89 \%)$ were in remission. The average time to relapse after the last infusion was much longer than in single injection studies: 19 days (s.d. = 13) after the last infusion. ${ }^{16}$ Investigators reported no worsening of cognitive function during the follow-up period although this was not formally tested.

Other researchers ${ }^{17,18}$ have sought to maintain the effect of i.v. ketamine by adding oral riluzole, a glutamatergic modulator with antidepressant and synaptic plasticity-enhancing effects, but this was unsuccessful. Future research should then explore new strategies to optimise the antidepressant response, including dosing regimens and routes of administration. ${ }^{9}$

To date, the field of psychiatry has paid little attention to the experience with oral and other non-intravenous administrations of ketamine for chronic pain. Ketamine is a well-known anaesthetic, with analgesic effects that may be used to treat chronic pain in a range of disorders. ${ }^{19}$ In the field of pain management, there is ample experience with the oral as well as i.v. application of ketamine. 
Indications for oral ketamine include neuropathic pain of various origins, complex regional pain syndrome, cancer pain, orofacial pain and phantom limb pain. As in depression, the therapeutic effect is believed to be based on antagonism of the NMDA receptor. ${ }^{20}$

This review describes the findings of these studies and combines the fields of pain management and depression, with special attention to safety, dosing regimen and treatment duration.

\section{Method}

We searched PubMed with the following terms: 'oral ketamine' AND 'depression'; 'oral ketamine' AND 'chronic pain' OR 'neuropathic pain'; 'intravenous ketamine' AND 'depression'; 'intravenous ketamine' AND 'chronic pain' OR 'neuropathic pain'; 'intranasal ketamine' AND 'depression'; 'intranasal ketamine' AND 'chronic pain' OR 'neuropathic pain'; and 'subcutaneous ketamine' AND 'depression' and 'subcutaneous ketamine' AND 'chronic pain' OR 'neuropathic pain' (final search date 27 October 2014). Our searches yielded 112 studies. We excluded literature reviews, studies with animals and studies with healthy individuals, thereby yielding 88 studies. We scanned all papers for information about study type and size, dosing regimen, number of individuals who received ketamine, number of ketamine days per study, results and side-effects. When these were described, we entered them into two tables (both available online). Table DS1 refers to the studies where ketamine was used to treat depression and Table DS2 refers to the studies where ketamine was used to treat pain. We designed two graphs with the information provided by those tables (Figs 1 and 2).

In total, for depression 4 studies were found using oral ketamine $(n=22), 43$ studies used intravenous ketamine ( $n=763), 2$ studies used intranasal ketamine $(n=19), 1$ study used sublingual ketamine $(n=26)$, and 2 case reports concerned intramuscular ketamine $(n=3)$. For pain, 12 studies used oral $(n=76), 21$ studies intravenous $(n=553), 2$ studies intranasal $(n=21)$ and 1 study intramuscular ketamine $(n=35)$. We found only one study on subcutaneous ketamine for pain that met the inclusion criteria, but it presented insufficient data (no dose and no number of ketamine days described), so we excluded it from the analysis. We found no subcutaneous ketamine for depression study. One sublingual ketamine for depression study and three intramuscular ketamine studies (one for pain and two for depression) were included in our analysis.

To compare dosing regimens across studies, we calculated the daily oral racemate equivalent dose, in $\mathrm{mg} / \mathrm{kg} /$ day, by multiplying the i.v. dose by five to correct for the five times lower average oral bioavailability $^{21,22}$ and by multiplying the $(S)$-ketamine dose by two to correct for the double potency relative to racemate. For intranasal dosing regimens, we obtained the daily oral racemate equivalent dose by multiplying them by 2.25 to correct for the 2.25 times lower oral bioavailability. ${ }^{23}$ In the case of intramuscular dosing regimens, we calculated the daily oral racemate equivalent dose by multiplying them by 4.65 to correct for the 4.65 times lower oral bioavailability. ${ }^{21}$ We multiplied the sublingual dose by 1.5 to obtain their daily oral racemate equivalent dose. ${ }^{23}$

\section{Results}

\section{Oral ketamine for depression}

Five uncontrolled, open-label studies were found that investigated the antidepressant properties of oral (including sublingual) ketamine. ${ }^{24-28}$ A small study $(n=4)$ found depression relief in patients with treatment-resistant unipolar or bipolar depression who were given up to $1.25 \mathrm{mg} / \mathrm{kg}$ oral $(S)$-ketamine for 2 weeks. ${ }^{24}$ In one study on palliative healthcare, ${ }^{25}$ the effects of ketamine on pain, anxiety and depression were assessed. This case report described a hospice patient who was treated daily with $40 \mathrm{mg}$ oral ketamine, which relieved all three complaints. Another hospicebased study described two severely ill and depressed patients who showed significant improvements lasting 1 or 2 weeks after a single oral dose of $0.5 \mathrm{mg} / \mathrm{kg}$ ketamine. ${ }^{26} \mathrm{~A}$ more recent

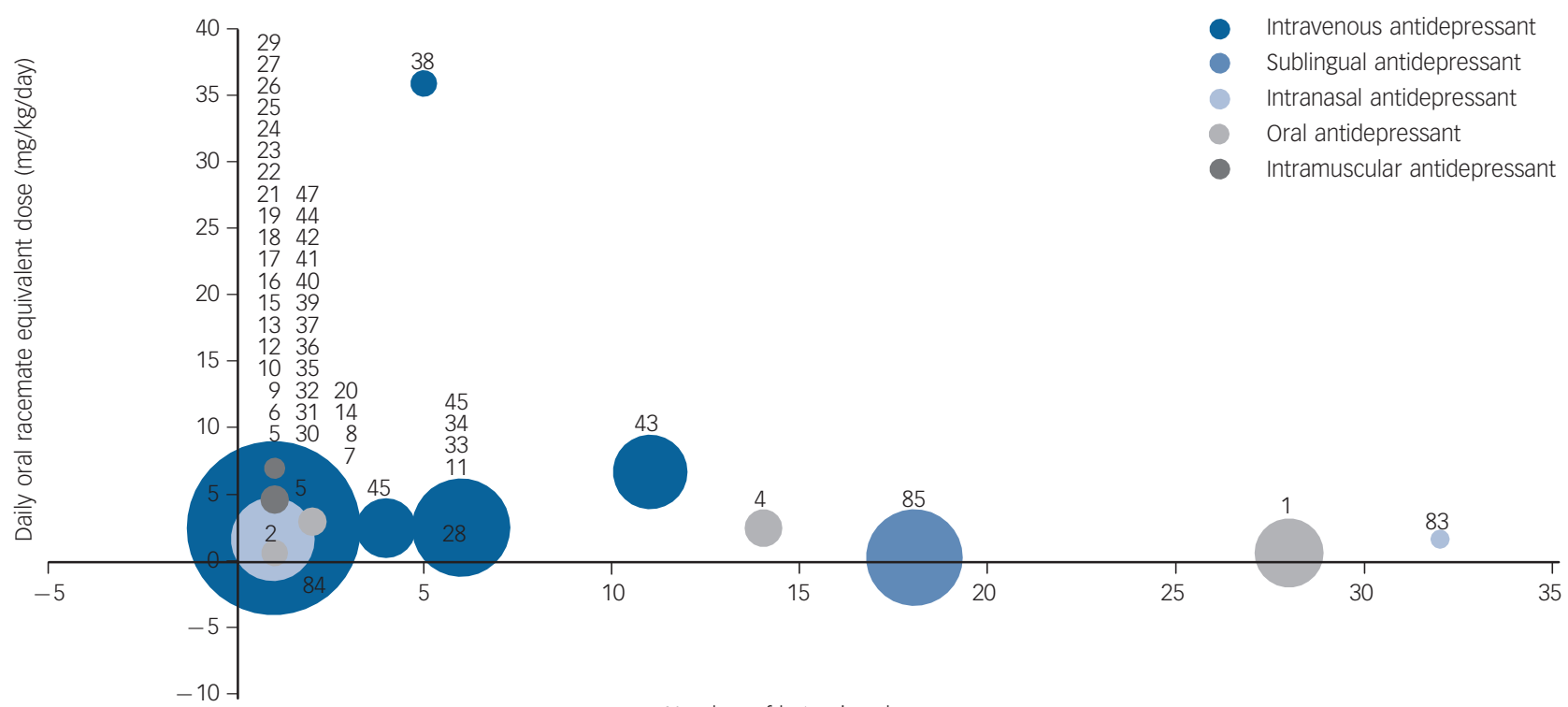

Number of ketamine days

Fig. 1 Overview of daily dose of ketamine for treating depression and number of ketamine days. Fifty-two studies about ketamine used to treat depression were included. The $x$-axis represents the number of ketamine days, which is different from the study duration. (In some studies, only one or few doses were given during a long follow-up time.) The size of the bubbles represents the size of the sample (number of individuals who received ketamine). The numbers close to the bubbles refer to the study identification, which can be found in Table DS1. 


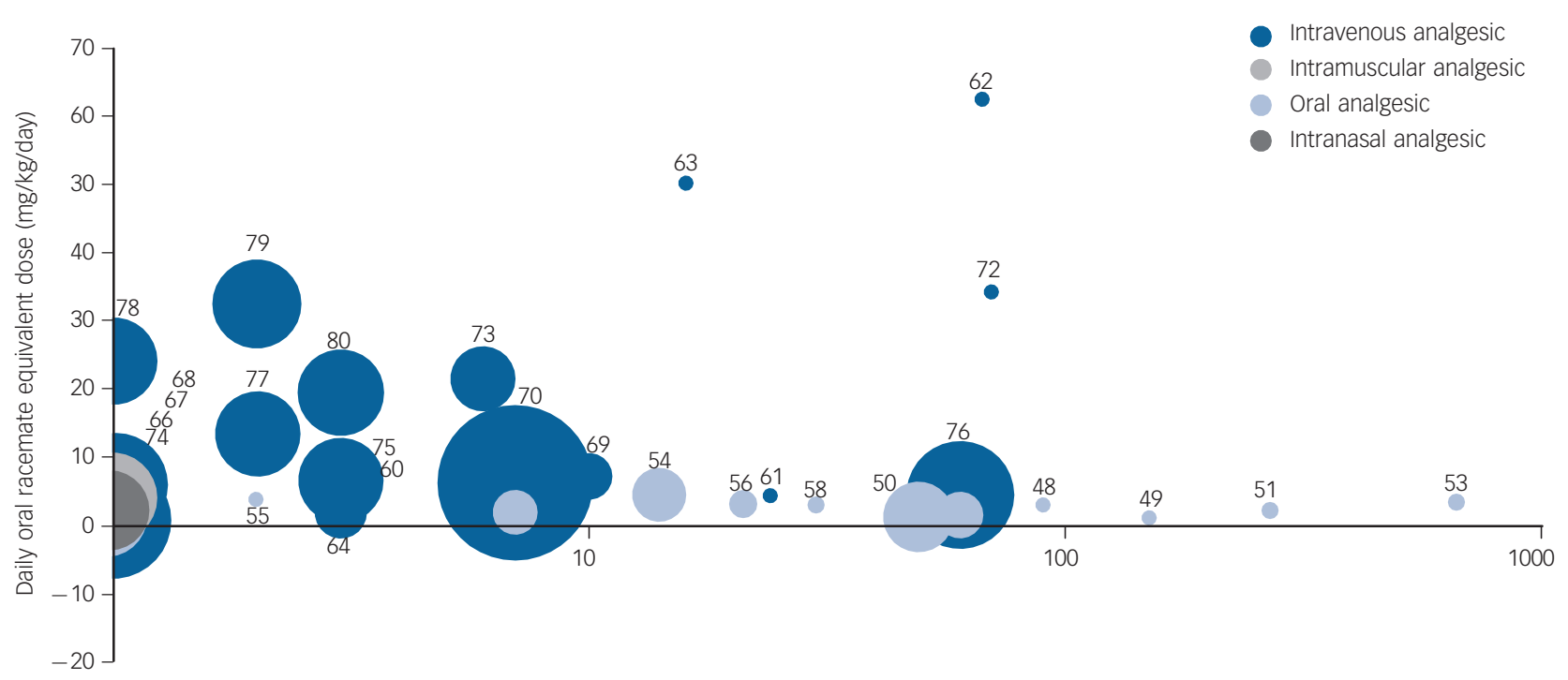

Number of ketamine days

Fig. 2 Overview of daily dose of ketamine for treating pain and number of ketamine days. Thirty-six studies about ketamine used for treating pain were included. The $x$-axis represents the number of ketamine days, which is different from the study duration. (In some studies, only one or few doses were given during a long follow-up time.) The size of the bubbles represents the size of the sample (number of individuals who received ketamine). The numbers close to the bubbles refer to the study identification, which can be found in Table DS2.

hospice-based study administered daily oral ketamine $(0.5 \mathrm{mg} / \mathrm{kg})$ over a 28-day period to patients in hospice care who had depressive symptoms. Eight out of 14 patients completed the trial and showed significant improvement in pain and depression with few side-effects. ${ }^{27}$ De Gioannis \& De Leo treated two patients with chronic suicidal ideation (and at least two significant past suicide attempts) with a solution of ketamine ingested with a flavoured drink. The maximum dose used was $3 \mathrm{mg} / \mathrm{kg}$ of ketamine. Both patients achieved sustained remission from suicidal ideation. ${ }^{28}$

Lara et al reported on $10 \mathrm{mg}$ sublingual ketamine, administered once, or every 2, 3 or 7 days for a total of up to 20 doses. They observed improved mood in 20 out of 26 patients with treatmentresistant unipolar or bipolar depression. The antidepressant effects outlasted the acute side-effects, which primarily concerned light-headedness, and which did not include euphoria or dissociation. $^{29}$

Clearly, these are only first indications of possible antidepressant effects of oral ketamine, as all of these studies were very small and uncontrolled, and the quality of the evidence was low.

\section{Dosing regimen and treatment duration of ketamine in chronic pain}

Figures 1 and 2 show that both for depression and pain most studies used the i.v. route of application. Expressed in daily oral racemate equivalent dose, the doses for depression are in the lower range compared with studies that investigated analgesic use. Also, the graphs show that ketamine as an antidepressant is generally given for shorter durations (1-32 days) than ketamine as an analgesic. Finally, it shows that on average i.v. ketamine is given for a shorter duration than oral ketamine. Studies with oral ketamine, where pain was the primary indication, administered ketamine once ${ }^{30}$ or for as long as 660 days, ${ }^{31}$ with most studies in the range of 20-80 days.

The doses used in the pain studies we analysed differed from the 0.1 daily oral racemate equivalent dose via oral administration $^{30}$ to $62.5 \mathrm{mg} / \mathrm{kg} /$ day intravenously. ${ }^{32}$ It is not possible to establish a dose-response association, but the majority of the pain studies we analysed describe ketamine as effective in reducing pain, even with low oral doses. The exceptions are six studies that used i.v. ketamine, ${ }^{33-38}$ which did not lead to any reduction in the pain scores. Although the study conducted by Kapural et al used a high dose (daily oral racemate equivalent dose of $21.5 \mathrm{mg} / \mathrm{kg} /$ day), it did not achieve an improvement in longterm pain scores in patients with high opioid requirements. ${ }^{33}$

Some studies in patients with chronic pain (that could be progressive or related to terminal illness) showed that patients required higher doses over time. For instance, Villanueva-Perez et al administered $30 \mathrm{mg}$ of oral ketamine every 8 hours to a patient with complex regional pain syndrome type 1 , increasing this dose weekly by $5 \mathrm{mg}$ until a maximum dose of $60 \mathrm{mg} / 6 \mathrm{~h}$ was reached. This patient kept this last dose for more than 2 years with significant improvement mainly in the first 17 months. ${ }^{31}$ Vick \& Lamer achieved significant improvement in pain, allodynia and hyperalgesia in one patient with central post-stroke pain at a dose of $50 \mathrm{mg}$ oral ketamine three times per day. This treatment lasted 3 months. ${ }^{39}$ This is in line with preclinical and clinical studies on anaesthesia and studies on ketamine misuse, that suggest that tolerance may develop. ${ }^{40-45}$

Clearly, the dosage is directly related to the bioavailability of ketamine. With oral administration the bioavailability is generally low, because of extensive first-pass metabolism. ${ }^{21}$ Reported values of oral ketamine in adults are in the range of $17-24 \%{ }^{21-23,46}$ A study by Brunette et al in children showed the highest bioavailability $(45 \%)$, and used a nasogastric tube and a $10 \mathrm{~mL}$ water flush, ${ }^{47}$ but Yanagihara et al also used a water flush $(100 \mathrm{~mL})$ and found a bioavailability of only $20 \%$ in adults. ${ }^{23}$ Other factors underlying the variability after oral dosing may include the formulation (tablet or solution, ketamine concentration), state of the stomach, dietary enzyme induction, and individual differences in cytochrome phenotype. It should be noted that interindividual pharmacokinetic variability is common to oral administration in general $^{48-50}$ and has also been described for currently prescribed antidepressants. ${ }^{51}$ Intranasal and sublingual ketamine administration 
have been reported to yield $45 \%$ and $30 \%$ bioavailability, respectively, ${ }^{23}$ but interindividual variability has been described for these routes of ketamine administration as well. ${ }^{52,53}$ Ketamine absorption after intramuscular injection has been described as more rapid, with a bioavailability of $93 \% .^{21}$

\section{Safety and abuse potential}

The most common side-effects of i.v. ketamine are psychotomimetic effects and dissociative symptoms, ${ }^{54}$ which correlate with high initial plasma levels and may thus be less pronounced in oral administration. ${ }^{55}$ Feeling 'high' after ketamine is also dependent on plasma levels. ${ }^{55}$ Other known side-effects are confusion, dizziness, euphoria, elevated blood pressure and increased libido, although all of these usually dissipate within $2 \mathrm{~h}$ of i.v. infusion. ${ }^{56}$

Ketamine neurotoxicity has been described in preclinical studies, ${ }^{57}$ but this was suggested to be due to the presence of the preservative chlorobutanol rather than to the ketamine itself. $^{58}$ Without preservative, ketamine can induce neurotoxicity when injected in very high doses into the subarachnoid space. ${ }^{59}$ The study by Sun et al showed that i.v. ketamine given to adolescent cynomolgus monkeys at a dose of $1 \mathrm{mg} / \mathrm{kg}$ in saline for 6 months might also produce permanent and irreversible deficits in brain function through the neurotoxic effect caused by the activation of the apoptotic pathway in the prefrontal cortex. ${ }^{60}$ This appears to be in contrast with studies in humans where ketamine was given in similar or higher doses with few mentions of cognitive problems. ${ }^{10,11}$ It should be noted that currently available clinical studies with i.v. ketamine used only one or few applications. In the studies involving pain, patients were given ketamine more often but mostly did not have the 'peak effect' of i.v. application. Prolonged ketamine misuse has been associated with white matter changes, ${ }^{61}$ memory changes, ${ }^{62}$ neurocognitive impairment ${ }^{54,63}$ and reduced well-being. ${ }^{54}$ Finally, inflammation and damage to the ureter and bladder are well documented in very heavy ketamine users who consume daily amounts of $1 \mathrm{~g}$ by inhalation and for prolonged periods of months or even years. ${ }^{64,65}$ Notably, in these studies daily doses were substantially higher than those used in clinical studies. Calculated in daily oral racemate equivalent dose, these users had approximately $80 \mathrm{mg} / \mathrm{kg} /$ day, which is 2.2 times higher than the highest daily oral racemate equivalent dose found in a study where ketamine was used to treat depression. ${ }^{66}$

The majority of the pain and depression studies retrieved by our search did not report the side-effects of oral ketamine as a major burden in treatment maintenance. Side-effects commonly mentioned were: dizziness, hallucinations, nausea, vomiting, drowsiness, confusion, light-headedness, headache, somnolence and anxiety. An exception to this is the study by Kannan et al involving nine patients with neuropathic pain, which stated that the beneficial effects in the management of intractable neuropathic pain were limited in some patients by adverse events such as nausea, vomiting, loss of appetite, drowsiness, sedation and feeling of unreality. ${ }^{67}$ Haines \& Gaines found that ketamine caused an analgesic response in only $14 \%$ of individuals and described that the adverse events (light-headedness, dizziness, tiredness, headache, nervous floating feeling and bad dreams) limited the use of ketamine in almost half of their patients. ${ }^{68}$ Side-effects commonly mentioned in studies using oral ketamine were lightheadedness or dizziness, nausea, vomiting, drowsiness, confusion, headache, somnolence, and having bad dreams. Hallucinations and paranoid feelings were reported in only one patient, ${ }^{31}$ and memory impairment and dysuria were reported in one study on 12 patients. $^{69}$

Very-low-dose sublingual administration of $10 \mathrm{mg}$ (approximately equivalent to $0.036 \mathrm{mg} / \mathrm{kg}$ i.v.) was not associated with euphoria, or psychotic and dissociative symptoms. ${ }^{29}$ In some studies, increased blood pressure was recorded when a benzodiazepine was administered concomitantly. ${ }^{70,71}$ The reported adverse events were usually limited to the ketamine treatment phase and did not persist after ketamine discontinuation (see online Tables DS1 and DS2 for more details on these side-effects).

Another concern with ketamine is its misuse potential, which has been demonstrated in both animals and humans. ${ }^{72,73}$ Ketamine has been used as a street drug since the 1960s, probably because of its rapid effects, its low cost and its specific psychotropic effects, such as hallucinatory and dissociative experiences (e.g. 'melting into the surrounding', 'out-of-body experiences') as well as 'giggliness. ${ }^{74,75}$ Multi-drug users who have used ketamine in large doses recreationally have also expressed concerns about its addictive properties. ${ }^{75}$ No studies compared different routes of ketamine administration directly, but the misuse potential is generally found to be higher with i.v. administration or inhalation that produces much more rapid and intensive effects compared to oral administration. ${ }^{76}$ In line with this, the psychedelic effects of ketamine are directly related to plasma concentrations. ${ }^{55}$ Importantly, in the pain studies mentioned earlier, addiction or misuse were not described as side-effects. Still, it is clear that these unwanted effects should be balanced against the possible beneficial properties of ketamine.

\section{Discussion}

Overall, the results suggest that oral ketamine in the described doses may be well tolerated. However, few studies have systematically studied its possible longer-term consequences. In comparison with studies of patients with pain, treatment duration in the currently available studies of depression is at the lower end of the spectrum. Further research is needed including basic science, acceptability and feasibility studies, ethical perspectives, and ultimately building to randomised trial designs. A number of issues need to be addressed. First, ketamine raises concerns, such as its potential for misuse, that warrant solid monitoring. Even though our review did not show such problems to be very important in studies on depression and pain, this may be much more of a problem if ketamine were to be used on a broader basis in clinical practice. We fully agree with the cautionary note of Schatzberg, ${ }^{77}$ who has signalled growing use without good evidence underlying it. It is also in line with the recent Cochrane review by Caddy et $a l^{78}$ that states that there is a need for studies examining the longer-term effects of repeated use of ketamine that also take into account oral and intramuscular routes. Both the short- and longer-term therapeutic effects as well as the possible side-effects of longer treatment duration of ketamine should be thoroughly assessed and reported before this could be applied on any scale in clinical practice. ${ }^{77}$

Second, even though the side-effect profile of oral ketamine seems to be milder than that reported in i.v. studies and in severe drug misusers, the overall safety profile would warrant that ketamine should be provided within a hospital setting. After an initial in-patient phase, oral ketamine might, however, be prescribed to depressed patients outside of the hospital environment for maintenance purposes, depending on an assessment of risk for each individual patient. Furthermore, side-effects should systematically be monitored using an instrument such as the Systematic Assessment for Treatment Emergent Events. ${ }^{79}$

Third, oral bioavailability of ketamine is rather low and variable, and studies should take into account blood levels and ketamine formulation. Fourth, as the antidepressant effects of ketamine may partially be related to its anaesthetic potential, 
especially in depressed patients with pain, a thorough assessment of both depressive symptoms and pain needs to be incorporated into upcoming trials.

Based on the above, we believe it is time to conduct rigorous RCTs that determine the benefits as well as possible unsolicited consequences of oral ketamine, given for weeks rather than days, for patients with treatment-resistant depression.

Robert A. Schoevers, MD PhD, Tharcila v. Chaves, MSC, Sonya M. Balukova MSc, University of Groningen, University Medical Center Groningen, Department of Psychiatry, Research School of Behavioural and Cognitive Neurosciences (BCN), Interdisciplinary Center for Psychopathology and Emotion Regulation (ICPE), Groningen; Marije aan het Rot, PhD, Department of Psychology and Research School of Behavioral and Cognitive Neurosciences; Rudie Kortekaas, PhD, Department of Psychiatry, Interdisciplinary Center for Psychopathology and Emotion Regulation, Department of Neuroscience, University Medical Center Groningen, University of Groningen, Groningen, The Netherlands

Correspondence: Robert A. Schoevers University Medical Center Groningen, Department of Psychiatry, Hanzeplein 1, P.O. Box 30001(CC-11), 9700 RB Groningen, The Netherlands. Email: r.a.schoevers@umcg.nl

First received 18 Apr 2014, final revision 21 Feb 2015, accepted 27 Feb 2015

\section{Acknowledgements}

We thank Robert Berman and Lisa Roach of Yale University School of Medicine for help with data mining.

\section{References}

1 Vollenweider FX, Kometer M. The neurobiology of psychedelic drugs: implications for the treatment of mood disorders. Nat Rev Neurosci 2010; 11 642-51.

2 Berman RM, Cappiello A, Anand A, Oren DA, Heninger GR, Charney DS, et al. Antidepressant effects of ketamine in depressed patients. Biol Psychiatry 2000; 47: 351-4.

3 Hashimoto K. Emerging role of glutamate in the pathophysiology of major depressive disorder. Brain Res Rev 2009; 61: 105-23.

4 Murrough JW. Ketamine as a novel antidepressant: from synapse to behavior Clin Pharmacol Ther 2012; 91: 303-9.

5 Moghaddam B, Adams B, Verma A, Daly D. Activation of glutamatergic neurotransmission by ketamine: a novel step in the pathway from NMDA receptor blockade to dopaminergic and cognitive disruptions associated with the prefrontal cortex. J Neurosci 1997; 17: 2921-7.

6 Zarate C Jr, Machado-Vieira R, Henter I, Ibrahim L, Diazgranados N, Salvadore G. Glutamatergic modulators: the future of treating mood disorders? Harv Rev Psychiatry 2010; 18: 293-303.

7 Li N, Lee B, Liu RJ, Banasr M, Dwyer JM, Iwata M, et al. mTOR-dependent synapse formation underlies the rapid antidepressant effects of NMDA antagonists. Science 2010; 329: 959-64.

8 Li N, Liu RJ, Dwyer JM, Banasr M, Lee B, Son H, et al. Glutamate $\mathrm{N}$-methyl-D-aspartate receptor antagonists rapidly reverse behavioral and synaptic deficits caused by chronic stress exposure. Biol Psychiatry 2011; 69: 754-61.

9 aan het Rot M, Zarate CA Jr, Charney DS, Mathew SJ. Ketamine for depression: where do we go from here? Biol Psychiatry 2012; 72: 537-47.

10 Diazgranados N, Ibrahim L, Brutsche NE, Newberg A, Kronstein P, Khalife S et al. A randomized add-on trial of an $\mathrm{N}$-methyl-D-aspartate antagonist in treatment-resistant bipolar depression. Arch Gen Psychiatry 2010; 67 793-802.

11 Zarate CA Jr, Brutsche NE, Ibrahim L, Franco-Chaves J, Diazgranados N, Cravchik A, et al. Replication of ketamine's antidepressant efficacy in bipola depression: a randomized controlled add-on trial. Biol Psychiatry 2012: 71: 939-46

12 Zarate CA Jr, Singh JB, Carlson PJ, Brutsche NE, Ameli R, Luckenbaugh DA et al. A randomized trial of an $\mathrm{N}$-methyl-D-aspartate antagonist in treatmentresistant major depression. Arch Gen Psychiatry 2006; 63: 856-64.

13 Sos P, Klirova M, Novak T, Kohutova B, Horacek J, Palenicek T. Relationship of ketamine's antidepressant and psychotomimetic effects in unipolar depression. Neuro Endocrinol Lett 2013; 34: 287-93.

14 Price RB, Iosifescu DV, Murrough JW, Chang LC, Al Jurdi RK, Iqbal SZ, et al Effects of ketamine on explicit and implicit suicidal cognition: a randomized controlled trial in treatment-resistant depression. Depress Anxiety 2014; 31 335-43.
15 Murrough JW, Iosifescu DV, Chang LC, Al Jurdi RK, Green CE, Perez AM, et al. Antidepressant efficacy of ketamine in treatment-resistant major depression: a two-site randomized controlled trial. Am J Psychiatry 2013; 170: 1134-42.

16 aan het Rot M, Collins KA, Murrough JW, Perez AM, Reich DL, Charney DS, et al. Safety and efficacy of repeated-dose intravenous ketamine for treatment-resistant depression. Biol Psychiatry 2010; 67: 139-45.

17 Ibrahim L, Diazgranados N, Franco-Chaves J, Brutsche N, Henter ID, Kronstein $\mathrm{P}$, et al. Course of improvement in depressive symptoms to a single intravenous infusion of ketamine vs add-on riluzole: results from a 4-week, double-blind, placebo-controlled study. Neuropsychopharmacology 2012; 37: 1526-33.

18 Mathew SJ, Murrough JW, aan het Rot M, Collins KA, Reich DL, Charney DS Riluzole for relapse prevention following intravenous ketamine in treatmentresistant depression: a pilot randomized, placebo-controlled continuation trial. Int J Neuropsychopharmacol 2010; 13: 71-82.

19 Blonk MI, Koder BG, van den Bemt PM, Huygen FJ. Use of oral ketamine in chronic pain management: a review. Eur J Pain 2010; 14: 466-72.

20 Fisher $\mathrm{K}$, Coderre TJ, Hagen NA. Targeting the $\mathrm{N}$-methyl-D-aspartate receptor for chronic pain management. Preclinical animal studies, recent clinical experience and future research directions. J Pain Symptom Manage 2000; 20: $358-73$.

21 Clements JA, Nimmo WS, Grant IS. Bioavailability, pharmacokinetics, and analgesic activity of ketamine in humans. J Pharm Sci 1982; 71: 539-42.

22 Chong CC, Schug SA, Page-Sharp M, Ilett KF. Bioavailability of ketamine after oral or sublingual administration. Pain Medicine 2006; 7: 469.

23 Yanagihara $\mathrm{Y}$, Ohtani M, Kariya S, Uchino K, Hiraishi T, Ashizawa N, et al. Plasma concentration profiles of ketamine and norketamine after administration of various ketamine preparations to healthy Japanese volunteers. Biopharm Drug Dispos 2003; 24: 37-43.

24 Paslakis G, Gilles M, Meyer-Lindenberg A, Deuschle M. Oral administration of the NMDA receptor antagonist S-ketamine as add-on therapy of depression: a case series. Pharmacopsychiatry 2010; 43: 33-5.

25 McNulty JP, Hahn K. Compounded oral ketamine. Int J Pharm Compd 2012; 16: $364-8$.

26 Irwin SA, Iglewicz A. Oral ketamine for the rapid treatment of depression and anxiety in patients receiving hospice care. J Palliat Med 2010; 13: 903-8.

27 Irwin SA, Iglewicz A, Nelesen RA, Lo JY, Carr CH, Romero SD, et al. Daily oral ketamine for the treatment of depression and anxiety in patients receiving hospice care: a 28-day open-label proof-of-concept trial. J Palliat Med 2013; 16: 958-65.

28 De Gioannis A, De Leo D. Oral ketamine augmentation for chronic suicidality in treatment-resistant depression. Aust NZ J Psychiatry 2014; 48: 686.

29 Lara DR, Bisol LW, Munari LR. Antidepressant, mood stabilizing and procognitive effects of very low dose sublingual ketamine in refractory unipolar and bipolar depression. Int J Neuropsychopharmacol 2013; 16: 2111-7.

30 Kaviani N, Khademi A, Ebtehaj I, Mohammadi Z. The effect of orally administered ketamine on requirement for anesthetics and postoperative pain in mandibular molar teeth with irreversible pulpitis. J Oral Sci 2011; 53 461-5.

31 Villanueva-Perez VL, Cerdá-Olmedo G, Samper JM, Mínguez A, Monsalve V, Bayona MJ, et al. Oral ketamine for the treatment of type I complex regional pain syndrome. Pain Pract 2007; 7: 39-43.

32 Klepstad P, Borchgrevink P, Hval B, Flaat S, Kaasa S. Long-term treatment with ketamine in a 12-year-old girl with severe neuropathic pain caused by a cervical spinal tumor. J Pediatr Hematol Oncol 2001; 23: 616-9.

33 Kapural L, Kapural M, Bensitel T, Sessler DI. Opioid-sparing effect of intravenous outpatient ketamine infusions appears short-lived in chronic-pain patients with high opioid requirements. Pain Physician 2010; 13: 389-94.

34 Joseph C, Gaillat F, Duponq R, Lieven R, Baumstarck K, Thomas P, et al. Is there any benefit to adding intravenous ketamine to patient-controlled epidural analgesia after thoracic surgery? A randomized double-blind study. Eur J Cardiothorac Surg 2012; 42: e58-65.

$35 \mathrm{Hu}$ J, Liao Q, Zhang F, Tong J, Ouyang W. Chronic postthoracotomy pain and perioperative ketamine infusion. J Pain Palliat Care Pharmacother 2014; 28 : $117-21$

36 Tena B, Gomar C, Rios J. Perioperative epidural or intravenous ketamine does not improve the effectiveness of thoracic epidural analgesia for acute and chronic pain after thoracotomy. Clin J Pain 2014; 30: 490-500.

37 Yazigi A, Abou-Zeid H, Srouji T, Madi-Jebara S, Haddad F, Jabbour K. The effect of low-dose intravenous ketamine on continuous intercostal analgesia following thoracotomy. Ann Card Anaesth 2012; 15: 32-8.

38 Barreveld AM, Correll DJ, Liu X, Max B, McGowan JA, Shovel L, et al. Ketamine decreases postoperative pain scores in patients taking opioids for 
chronic pain: results of a prospective, randomized, double-blind study. Pain Med 2013; 14: 925-34.

39 Vick PG, Lamer TJ. Treatment of central post-stroke pain with oral ketamine. Pain 2001; 92: 311-3.

40 Pouget P, Wattiez N, Rivaud-Péchoux S, Gaymard B. Rapid development of tolerance to sub-anaesthetic dose of ketamine: an oculomotor study in macaque monkeys. Psychopharmacology (Berl) 2010; 209: 313-8.

41 Rocha BA, Ward AS, Egilmez Y, Lytle DA, Emmett-Oglesby MW. Tolerance to the discriminative stimulus and reinforcing effects of ketamine. Behav Pharmacol 1996; 7: 160-8.

42 Stevens RW, Hain WR. Tolerance to rectal ketamine in paediatric anaesthesia. Anaesthesia 1981; 36: 1089-93.

43 Byer $D E$, Gould $A B$ Jr. Development of tolerance to ketamine in an infant undergoing repeated anesthesia. Anesthesiology 1981; 54: 255-6.

44 Livingston A, Waterman AE. The development of tolerance to ketamine in rats and the significance of hepatic metabolism. Br J Pharmacol 1978; 64: 63-9.

45 Cumming JF. The development of an acute tolerance to ketamine. Anesth Analg 1976; 55: 788-91.

46 Chong C, Schug SA, Page-Sharp M, Jenkins B, Ilett KF. Development of a sublingual/oral formulation of ketamine for use in neuropathic pain: preliminary findings from a three-way randomized, crossover study. Clin Drug Investig 2009; 29: 317-24.

47 Brunette KE, Anderson BJ, Thomas J, Wiesner L, Herd DW, Schulein S. Exploring the pharmacokinetics of oral ketamine in children undergoing burns procedures. Paediatr Anaesth 2011; 21: 653-62.

48 Zimm S, Collins JM, Riccardi R, O'Neill D, Narang PK, Chabner B, et al. Variable bioavailability of oral mercaptopurine. Is maintenance chemotherapy in acute lymphoblastic leukemia being optimally delivered? N Engl J Med 1983; 308: 1005-9.

49 Harvey VJ, Slevin ML, Joel SP, Smythe MM, Johnston A, Wrigley PF. Variable bioavailability following repeated oral doses of etoposide. Eur J Cancer Clin Oncol 1985; 21: 1315-9.

50 Di WL, Kadva A, Johnston A, Silman R. Variable bioavailability of oral melatonin. N Engl J Med 1997; 336: 1028-9.

51 Lund J, Thayssen P, Mengel H, Pedersen OL, Kristensen CB, Gram LF. Paroxetine: pharmacokinetics and cardiovascular effects after oral and intravenous single doses in man. Acta Pharmacol Toxicol (Copenh) 1982; 51 351-7.

52 Weber $\mathrm{F}$, Wulf $\mathrm{H}$, Gruber M, Biallas R. S-ketamine and s-norketamine plasma concentrations after nasal and i.v. administration in anesthetized children. Paediatr Anaesth 2004; 14: 983-8.

53 Rolan P, Lim S, Sunderland V, Liu Y, Molnar V. The absolute bioavailability of racemic ketamine from a novel sublingual formulation. Br J Clin Pharmacol 2014; 77: 1011-6.

54 Morgan CJ, Muetzelfeldt L, Curran HV. Consequences of chronic ketamine self-administration upon neurocognitive function and psychological wellbeing: a 1-year longitudinal study. Addiction 2010; 105: 121-33.

55 Bowdle TA, Radant AD, Cowley DS, Kharasch ED, Strassman RJ, Roy-Byrne PP. Psychedelic effects of ketamine in healthy volunteers: relationship to steady-state plasma concentrations. Anesthesiology 1998; 88: 82-8.

56 Liebrenz M, Borgeat A, Leisinger R, Stohler R. Intravenous ketamine therapy in a patient with a treatment-resistant major depression. Swiss Med Wkly 2007; 137: 234-6.

57 Malinovsky JM, Cozian A, Lepage JY, Mussini JM, Pinaud M, Souron R. Ketamine and midazolam neurotoxicity in the rabbit. Anesthesiology 1991; 75: 91-7.

58 Malinovsky JM, Lepage JY, Cozian A, Mussini JM, Pinaudt M, Souron R. Is ketamine or its preservative responsible for neurotoxicity in the rabbit? Anesthesiology 1993; 78: 109-15.
59 Gomes LM, Garcia JB, Ribamar JS Jr, Nascimento AG. Neurotoxicity of subarachnoid preservative-free S(+)-ketamine in dogs. Pain Physician 2011; 14: 83-90.

60 Sun L, Li Q, Li Q, Zhang Y, Liu D, Jiang $H$, et al. Chronic ketamine exposure induces permanent impairment of brain functions in adolescent cynomolgus monkeys. Addict Biol 2014; 19: 185-94.

61 Edward Roberts R, Curran HV, Friston KJ, Morgan CJ. Abnormalities in white matter microstructure associated with chronic ketamine use. Neuropsychopharmacology 2014; 39: 329-38.

62 Freeman TP, Morgan CJ, Pepper F, Howes OD, Stone JM, Curran HV. Associative blocking to reward-predicting cues is attenuated in ketamine users but can be modulated by images associated with drug use. Psychopharmacology (Berl) 2013; 225: 41-50.

63 Morgan CJ, Curran HV, Independent Scientific Committee on Drugs. Ketamine use: a review. Addiction 2012; 107: 27-38.

64 Shahani R, Streutker C, Dickson B, Stewart RJ. Ketamine-associated ulcerative cystitis: a new clinical entity. Urology 2007; 69: 810-2.

65 Tsai TH, Cha TL, Lin CM, Tsao CW, Tang SH, Chuang FP, et al. Ketamineassociated bladder dysfunction. Int J Urol 2009; 16: 826-9.

66 Correll GE, Futter GE. Two case studies of patients with major depressive disorder given low-dose (subanesthetic) ketamine infusions. Pain Med 2006; 7: $92-5$.

67 Kannan TR, Saxena A, Bhatnagar S, Barry A. Oral ketamine as an adjuvant to oral morphine for neuropathic pain in cancer patients. J Pain Symptom Manage 2002; 23: 60-5.

68 Haines DR, Gaines SP. N of 1 randomised controlled trials of oral ketamine in patients with chronic pain. Pain 1999; 83: 283-7.

69 Bredlau AL, McDermott MP, Adams HR, Dworkin RH, Venuto C, Fisher SG, et al. Oral ketamine for children with chronic pain: a pilot phase I study. J Pediatr 2013; 163: 194-200.

70 Mercadante S, Arcuri E, Tirelli W, Casuccio A. Analgesic effect of intravenous ketamine in cancer patients on morphine therapy: a randomized, controlled, double-blind, crossover, double-dose study. J Pain Symptom Manage 2000; 20: $246-52$.

71 Schwartzman RJ, Alexander GM, Grothusen JR, Paylor T, Reichenberger E, Perreault M. Outpatient intravenous ketamine for the treatment of complex regional pain syndrome: a double-blind placebo controlled study. Pain 2009; 147: 107-15.

72 Beardsley PM, Balster RL. Behavioral dependence upon phencyclidine and ketamine in the rat. J Pharmacol Exp Ther 1987; 242: 203-11.

73 Klein M, Calderon S, Hayes B. Abuse liability assessment of neuroprotectants. Ann NY Acad Sci 1999; 890: 515-25.

74 Corazza O, Assi S, Schifano F. From "Special K" to "Special M": the evolution of the recreational use of ketamine and methoxetamine. CNS Neuroscience Ther 2013; 19: 454-60.

75 Muetzelfeldt L, Kamboj SK, Rees H, Taylor J, Morgan CJ, Curran HV. Journey through the K-hole: phenomenological aspects of ketamine use. Drug Alcohol Depend 2008; 95: 219-29.

76 Argoff CE, Stanos SP, Wieman MS. Validity testing of patient objections to acceptance of tamper-resistant opioid formulations. J Pain Res 2013; 6 : 367-73.

77 Schatzberg AF. A word to the wise about ketamine. Am J Psychiatry 2014; 171: $262-4$.

78 Caddy C, Amit BH, McCloud TL, Rendell JM, Furukawa TA, McShane R, et al. Ketamine and other glutamate receptor modulators for depression in adults. Cochrane Database Syst Rev 2015; 9: CD011612.

79 Levine J, Schooler NR. SAFTEE: a technique for the systematic assessment of side effects in clinical trials. Psychopharmacol Bull 1986; 22: 343-81. 